\title{
OXYTOCIN GIVEN AS IV BOLUS VERSUS IV INFUSION IN WOMEN UNDERGOING CAESAREAN SECTION- A RANDOMISED, CONTROLLED, DOUBLE-BLIND STUDY
}

\author{
Ruchi Tandon'1, Tahir Ali Khan², Shikha Mehrotra ${ }^{3}$ \\ ${ }_{1}^{1}$ Associate Professor, Department of Anaesthesiology, Gandhi Medical College, Bhopal, Madhya Pradesh. \\ ${ }^{2}$ Associate Professor, Department of Anaesthesiology and Critical Care, Chirayu Medical College and Hospital, Bhopal, Madhya Pradesh. \\ 3Professor, Department of Anaesthesiology, Gandhi Medical College, Bhopal, Madhya Pradesh.
}

\section{ABSTRACT}

\section{BACKGROUND}

Oxytocin is the uterotonic of choice in the prevention of uterine atony. It reduces blood loss during both vaginal deliveries(1) and caesarean sections. Its prophylactic and therapeutic administration is justified, because it is said to reduce the incidence of PPH by about $40 \%$. However, bolus use of oxytocin is known to cause cardiovascular effects including tachycardia, hypotension and ST changes.

Aims and Objectives- To compare the uterine tone, blood loss and haemodynamic responses on intravenous administration of oxytocin 5 units given as IV bolus or IV infusion in women undergoing Caesarean section under sub-arachnoid block.

\section{MATERIALS AND METHODS}

This is a randomised, controlled, double-blind study. 80 patients were allocated into two groups. Sample is considered conveniently-

1. Group I: To receive 5 units of oxytocin over 5 seconds (Bolus).

2. Group II: To receive 5 units of oxytocin in $15 \mathrm{~mL}$ NS over 5 minutes (Infusion).

\section{RESULTS}

Heart rate (beat/min) effect of oxytocin given intravenous bolus vs. infusion showed statistically significant difference from 1 minute to 5 minutes $(\mathrm{p}<0.05)$. Similarly, mean arterial pressure (MAP) rate (beast/min) effect of oxytocin given intravenous bolus vs. infusion also showed statistically significant difference from 1 minute to 5 minutes $(\mathrm{p}<0.05)$.

\section{CONCLUSION}

We recommend that bolus doses should be avoided or to be used with caution, and further studies should ascertain if oxytocin is equally effective in reducing blood loss when given at a slower rate.

\section{KEYWORDS}

Haemodynamic Changes, Oxytocin Bolus, Oxytocin Infusion, Caesarean Section.

HOW TO CITE THIS ARTICLE: Tandon R, Khan TA, Mehrotra S. Oxytocin given as IV bolus versus IV infusion in women undergoing caesarean section- a randomised, controlled, double-blind study. J. Evolution Med. Dent. Sci. 2018;7(11):1423-1425, DOI: $10.14260 /$ jemds/2018/323

\section{BACKGROUND}

Oxytocin remains the uterotonic of choice to prevent uterine atony and its prophylactic and therapeutic administration after delivery whether spontaneous or operative is justified, because it is said to reduce the incidence of PPH by about $40 \%$.(1) However, ideal dose and mode of administration is still not established.(2),(3),(4) Large doses of oxytocin is known to cause adverse effects including hypotension, nausea, vomiting, chest pain, headache, flushing, myocardial ischaemia, ST changes, pulmonary oedema and severe water intoxication with convulsions.(2),(3),(5) These effects are particularly important when administered in high doses or in bolus, more so in parturient with hypovolaemia or preexisting alterations in CVS. However, these effects are not

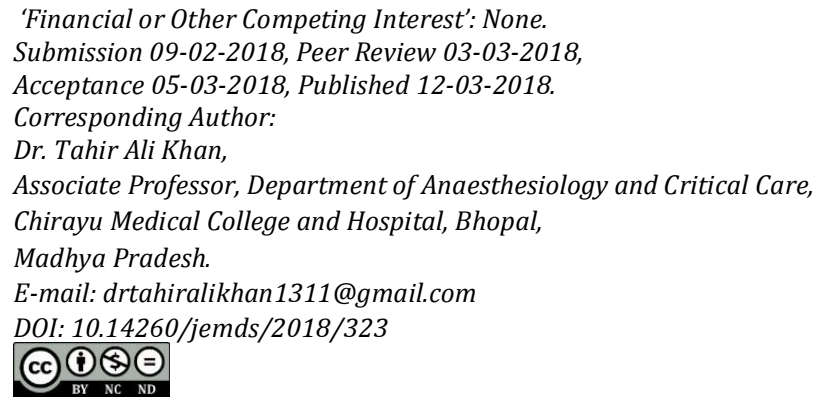

widely appreciated by clinicians as highlighted in the Confidential Enquiry into Maternal Deaths (CEMD) published in 2001.(6),(7) Pinder et al studied the haemodynamic effects of IV bolus doses ( $5 \mathrm{u} \mathrm{v} / \mathrm{s} 10 \mathrm{u}$ ) of oxytocin in women undergoing caesarean section under spinal anaesthesia and confirmed the dose related effects of oxytocin. An inadequate dose on the other hand carries the risk of increased uterine bleeding and associated complications. The exact dose and method of administration of oxytocin is still a topic of discussion in obstetric anaesthesia.(8) Changes in heart rate, blood pressure, cardiac output, esp. in caesarean section surgeries have also been put forth in other studies by Langesaeter $\mathrm{E}$ et al and M. Petersson. $(9,10)$ Keeping these facts in mind, we wanted to see whether way of administration of oxytocin i.e. IV bolus versus IV infusion had any effect on haemodynamics of patients undergoing caesarean section under spinal anaesthesia.

\section{MATERIALS AND METHODS}

This was a randomised, controlled, double-blind study. With this background, this study was undertaken in the Department of Anaesthesiology, Gandhi Medical College and associated Sultania Zanana Hospital, Bhopal, after obtaining clearance from Institutional Ethics Committee. Sample is considered conveniently 80 healthy full-term parturients of ASA grade I and II undergoing caesarean section under SAB 
were included in this randomised, controlled, double-blinded study with the objective to compare the uterine tone, blood loss and haemodynamic responses along with adverse effects on intravenous administration of oxytocin 5 units given as IV bolus or infusion over 5 minutes. Patients with any known risk factor for uterine atony or cardiovascular instability like placenta praevia, pregnancy induced hypertension, prolonged labour and leiomyomata were excluded from the study, so were the patients who were given oxytocin for induction of labour.

After taking informed consent, patients were divided into two groups (Randomisation done using the envelope method) on the basis of oxytocin administration at the time of cord clamping-

Group I: To receive 5 units of oxytocin over 5 seconds (Bolus).

Group II: To receive 5 units of oxytocin in $15 \mathrm{~mL}$ NS over 5 minutes (Infusion).

IV line was secured, and all patients were administered 10-15 mL/kg of lactated ringer solution with Inj. Ranitidine $50 \mathrm{mg}$ IV and Inj. Metoclopramide $10 \mathrm{mg}$ IV.

Routine monitors were attached and preoperative HR, BP, $\mathrm{RR}$ and SpO2 were recorded. Sub-arachnoid block was administered using Bupivacaine $0.5 \%$ heavy $12.5 \mathrm{mg}(2.5$ $\mathrm{mL}$ ) via 25-G spinal needle in L3-L4 space in left lateral position. All patients were given supplemental oxygen. Level of sensory blockade was assessed by pinprick method and surgery was commenced once a level of T4-T6 was achieved.

For the purpose of study, the blood pressure and pulse rate at the time of delivery of the baby were regarded as baseline values. Maternal BP and HR values were computed as \% changes from baseline. Change in BP and HR was regarded as significant if it was $10 \%$ or more of baseline.

Fall in BP $>30 \%$ of the preoperative values at any moment during the surgery was treated with IV ephedrine $6 \mathrm{mg}$ and these patients were not included further in the study. Pulse rate and blood pressure were recorded just before the delivery of the baby and were regarded as baseline values.

Oxytocin was started at the time of cord clamping in Group I as 5 IU given over 5 secs and in patients of Group II as $5 \mathrm{IU}$ diluted to $15 \mathrm{~mL}$ normal saline given over 5 minutes using an infusion pump.

Mean arterial pressure (MAP) and heart rate were recorded at 1, 2, 3, 5, 10, 15, 20 and 30 minutes from the start of oxytocin infusion.

Uterine tone was assessed subjectively (there being no method of assessing the same objectively) by a blinded obstetrician as satisfactory or not at 3 and 5 mins from the delivery of the baby.

Subsequent to completion of oxytocin 5 IU bolus or 5 IU via infusion pump estimated blood loss was assessed by a blinded assistant and adverse effects like nausea, vomiting, chest discomfort, headache and flushes were noted in both the groups.
Requirement of additional uterotonics was also noted and the protocol for additional uterotonics followed in our study was additional $5 \mathrm{IU}$ oxytocin followed by Methylergometrine $0.2 \mathrm{mg}$ IV followed by Carboprost $0.25 \mathrm{mg}$ IM.

\section{Statistical Analysis}

The qualitative data were expressed in proportion and percentages and the quantitative data expressed as mean and standard deviations. The difference in proportions was analysed using chi-square test and the difference in means were analysed using student ' $T$ ' Test. Significance level for tests was determined as $95 \%(\mathrm{p}<0.05)$.

RESULTS

Demographic Profile

\begin{tabular}{|c|c|c|}
\hline Data & Group I & Group II \\
\hline Age (years) & $26.4+/-3.4$ & $25.6+/-2.6$ \\
\hline Weight $(\mathrm{kg})$ & $61.2+/-6.1$ & $62.7+/-6.7$ \\
\hline Height $(\mathrm{cm})$ & $158+/-13.42$ & $159+/-11.6$ \\
\hline \multicolumn{3}{|c|}{ Table 1 } \\
\hline
\end{tabular}

The two groups were similar in terms of age, weight and height (Table 1), as their difference was statistically insignificant and therefore comparable for this study.

Mean Arterial Pressure

\begin{tabular}{|c|c|c|c|c|c|}
\hline & \multicolumn{2}{|c|}{ Group I } & \multicolumn{2}{c|}{ Group II } & P value \\
\hline $\begin{array}{c}\text { Pre- } \\
\text { operative }\end{array}$ & \multicolumn{2}{|c|}{$\mathbf{9 0 . 2 + / - 4 . 9}$} & \multicolumn{2}{|c|}{$\mathbf{9 1 . 8 + / - 4 . 1}$} & $>\mathbf{0 . 0 5}$ \\
\hline Baseline & $\begin{array}{c}78.4+/- \\
5.3\end{array}$ & $\begin{array}{c}\text { \% change } \\
\text { from } \\
\text { baseline }\end{array}$ & $\begin{array}{c}77.9+/- \\
4.8\end{array}$ & $\begin{array}{c}\text { \% change } \\
\text { from } \\
\text { baseline }\end{array}$ & $>0.05$ \\
\hline 1 min & $\begin{array}{c}62.3+/- \\
.2\end{array}$ & $-21.9 \%$ & $\begin{array}{c}75.2+/- \\
3.7\end{array}$ & $-3.5 \%$ & $<0.05 \%$ \\
\hline 2 mins & $\begin{array}{c}66.1+/- \\
4.4\end{array}$ & $-15.7 \%$ & $\begin{array}{c}69.3+/- \\
5.9\end{array}$ & $-11.8 \%$ & $>0.05$ \\
\hline 3 mins & $\begin{array}{c}70.4+/- \\
4.5\end{array}$ & $-10.3 \%$ & $\begin{array}{c}69.5+/- \\
4.1\end{array}$ & $-11.9 \%$ & $>0.05$ \\
\hline 10 mins & $\begin{array}{c}76.6+/- \\
3.2\end{array}$ & $-3.3 \%$ & $\begin{array}{c}71.1+/- \\
6.9\end{array}$ & $-8.8 \%$ & $>0.05$ \\
\hline 15 mins & $\begin{array}{c}79.1+/- \\
6.1\end{array}$ & $-0.8 \%$ & $\begin{array}{c}76.4+/- \\
4.8\end{array}$ & $-1.9 \%$ & $>0.05$ \\
\hline \multicolumn{5}{|c|}{ Table 2 } \\
\hline
\end{tabular}

There was a statistically significant difference in maximum fall in BP between the two groups with a maximum fall of $21.9 \%$ from baseline in bolus group as compared to $11.98 \%$ in infusion group.

Also, the maximum fall in BP in bolus group was seen at 1 min as compared to infusion group, where the maximum fall in BP was seen at 3 mins onwards from the start of infusion.

There were 6 patients in the bolus group whose BP decreased more than $30 \%$ of preoperative value at 1 min ( 5 patients) and 2 minutes ( 1 patient) as compared to 1 patient in infusion group at 3 minutes. 
Heart Rate

\begin{tabular}{|c|c|c|c|c|c|}
\hline & \multicolumn{2}{|c|}{ Group I } & \multicolumn{2}{c|}{ Group II } & $\begin{array}{c}\text { P } \\
\text { value }\end{array}$ \\
\hline $\begin{array}{c}\text { Pre- } \\
\text { Operative }\end{array}$ & \multicolumn{2}{|c|}{$\mathbf{9 0 . 2 + / - 4 . 7}$} & \multicolumn{2}{c|}{$\mathbf{8 8 . 9 + / - 4 . 3}$} & $>\mathbf{0 . 0 5}$ \\
\hline Baseline & $\begin{array}{c}98.4+/- \\
4.2\end{array}$ & $\begin{array}{c}\text { \% change } \\
\text { from } \\
\text { baseline }\end{array}$ & $\begin{array}{c}94.1+/- \\
4.3\end{array}$ & $\begin{array}{c}\text { \% change } \\
\text { from } \\
\text { baseline }\end{array}$ & $>0.05$ \\
\hline 1 min & $\begin{array}{c}109.3+/- \\
5.1\end{array}$ & $+17 \%$ & $\begin{array}{c}98.2+/- \\
3.7\end{array}$ & $+4.2 \%$ & $<0.05$ \\
\hline 2 mins & $\begin{array}{c}98.2+/- \\
3.3\end{array}$ & $+5.1 \%$ & $\begin{array}{c}102.6+/- \\
6.9\end{array}$ & $+9.1 \%$ & $>0.05$ \\
\hline 3 mins & $\begin{array}{c}95.7+/- \\
4.4\end{array}$ & $+2.4 \%$ & $\begin{array}{c}102.3+/- \\
3.1\end{array}$ & $+8.9 \%$ & $>0.05$ \\
\hline 5 mins & $\begin{array}{c}92.1+/- \\
3.1\end{array}$ & $-1.4 \%$ & $\begin{array}{c}98.4+/- \\
6.8\end{array}$ & $+3.8 \%$ & $>0.05$ \\
\hline 10 mins & $\begin{array}{c}93.2+/- \\
4.8\end{array}$ & $-0.3 \%$ & $\begin{array}{c}96.2+/- \\
4.7\end{array}$ & $+1.1 \%$ & $>0.05$ \\
\hline 15 mins & $\begin{array}{c}92.6+/- \\
4.9\end{array}$ & $-0.9 \%$ & $\begin{array}{c}94.7+/- \\
3.7\end{array}$ & $+0.9 \%$ & $>0.05$ \\
\hline \multicolumn{5}{|c|}{ Table 3 } \\
\hline
\end{tabular}

There was a statistically significant difference in maximum increase in heart rate between the two groups with a maximum increase of $17 \%$ from baseline in bolus group as compared to only $4.2 \%$ in infusion group.

Also the maximum increase in heart rate in bolus group was seen at $1 \mathrm{~min}$ as compared to infusion group, where it was observed at 3 mins onwards from the start of infusion.

\section{Uterine Tone and Need for Additional Uterotonics}

\begin{tabular}{|c|c|c|c|c|c|}
\hline Time & \multicolumn{2}{|c|}{ Group I } & \multicolumn{2}{c|}{ Group II } & P value \\
\hline & Adequate & Inadequate & Adequate & Inadequate & \\
\hline 3 mins & 39 & 1 & 38 & 2 & $>0.05$ \\
\hline 5 mins & 39 & 1 & 38 & 2 & $>0.05$ \\
\hline \multicolumn{6}{|c|}{ Table 4 } \\
\hline
\end{tabular}

There was no statistically significant difference in the uterine tone between the two groups.

Of the three patients 1 patient required additional 5 units Oxytocin, whereas 2 patients required Methylergometrine.

\section{Blood Loss}

\begin{tabular}{|c|c|c|c|}
\hline & Group I & Group II & P value \\
\hline Blood Loss in mL & $760+/-14$ & $740+/-12$ & $>0.05$ \\
\hline \multicolumn{4}{|c|}{ Table 5 } \\
\hline
\end{tabular}

There was no statistically significant difference in blood loss between the two groups.

\section{DISCUSSION}

As seen in our study, the variation in MAP in bolus group was more abrupt with maximal fall seen 1 min after the bolus and the fall in MAP was statistically significant $(21.9 \%$ from the baseline); thereafter, the MAP returned within normal range of baseline within 3 minutes. Likewise, pulse rate trends in bolus group showed a significant tachycardia at 1 min with an increase of $17.1 \%$ from baseline and the rate returning to within normal limits in 2 mins. Thus, it could be said that 5 units bolus administration of oxytocin results in significant alteration in haemodynamics in first minute of administration, which may take 2 to 3 minutes to return to normal. Whilst decrease in MAP of such magnitude may be well tolerated normally, it may not be desirable if there is concomitant severe blood loss or when there is unsuspected cardiovascular disease. In contrast to bolus administration, oxytocin infusion over 5 minutes resulted in lesser haemodynamic alterations and that too occurring at a relatively longer interval, thus allowing the maternal CVS to compensate. It was also seen that there were no significant difference in uterine tone, blood loss, need for additional uterotonics or between the two groups.

\section{LIMITATION OF THE STUDY}

Due to short duration of study, convenience sampling technique was followed. Thus, sampling size was also calculated by convenience. The results of the study cannot be generalised due to the potential bias resulting from the sampling technique and sample size estimation.

\section{CONCLUSION}

We recommend that bolus doses should be avoided or to be used with caution, and further studies should ascertain if oxytocin is equally effective in reducing blood loss when given at a slower rate.

Our study shows that slower injection of oxytocin can effectively minimise the cardiovascular side-effects of a bolus dose without compromising the therapeutic benefits.

In summary, this study supports the need for cautious use of oxytocin as a bolus, especially in patients having cardiovascular instability and offers relative reassurance of the effects when given as an infusion over 5 mins.

\section{REFERENCES}

[1] Hashami U, Subohi S. Prophylactic use of oxytocin versus oxytocin plus ergometrin for preventic of postpartum hemorrhage. J Surg Pak 2006;11:56-8.

[2] Thomas JS, Koh SH, Cooper GM. Haemodynamic effects of oxytocin given as i.v. bolus or infusion on women undergoing caesarean section. $\mathrm{Br} \mathrm{J}$ Anaesth 2007;98(1):116-9.

[3] Pinder AJ, Dresner M, Calow C, et al. Haemodynamic changes caused by oxytocin during caesarean section under spinal anaesthesia. Int J Obstet Anesth 2002;11(3):156-9.

[4] Hendricks CH, Brenner WE. Cardiovascular effects of oxytocic drugs used post partum. Am J Obstet Gynecol 1970;108(5):751-60.

[5] Michelini LC, Marcelo MC, Amico J, et al. Oxytocinergic regulation of cardiovascular function: studies in oxytocin-deficient mice. Am J Physiol Heart Circ Physiol 2003;284(6):H2269-76.

[6] Weis FR, Markello R, Mo B, et al. Cardiovascular effects of oxytocin. Obstet Gynecol 1975;46(2):211-4.

[7] British National Formulary. London: British Medical Association and the Royal Pharmaceutical Society of Great Britain, 2001:376.

[8] Scrutton M. Update in obstetric anaesthesia oxytocin: what dose and why? Anaesthesia Points West 2004;37:28-30.

[9] Langesaeter E, Rosseland LA, Stubhaug A. Hemodynamic effects of oxytocin during cesarean delivery. Int J Gynaecol Obstet 2006; 95(1):46-7.

[10] Petersson M. Cardiovascular effects of oxytocin. Prog Brain Res 2002;139:281-8. 